are not used, then the papers and discussion that follow will be absorbing. If you find yourself wanting more detailed discussion of the assumptions that $\mathrm{Mr}$ Baird makes in his introduction, you may be left slightly dissatisfied.

Reading through the papers, it soon becomes apparent that the reasons why women seek abortion appear to be far removed from a desire to prevent an unlimited growth of the world's population. In the United Kingdom, 98 per cent of women wish to have an abortion because of social reasons; often it is a first pregnancy. This picture appears to be reflected in other countries. The factors that influence women to take such decisions are not really discussed in this text and it is, I feel, a regrettable omission.

However, many issues are raised in the book which should provoke the reader into reflecting on his or her own ethics and practices and this is one of the strengths of presenting subject matter in this way. One of the contributors argues that it could be considered unethical to train more doctors than are necessary, as they will have to gain experience that they will never utilise at the expense of vulnerable women. Alastair Campbell spends some time discussing how the terms 'illegal' and 'untrained' are often seen as synonymous when discussing abortion. It is evident from some of the papers that legal abortions are, on occasion, performed by inexperienced personnel, whereas illegal abortions performed in certain countries, are performed by highly experienced personnel. Legality it would seem may not always be synonymous with experience or safety. The availability of abortion is also discussed. Lidija Andolsek states that abortion is seen as a basic human right in Slovenia, a statement which 'pro-life' organisations may well see as a contradiction in terms, but certainly it is an issue worthy of more detailed discussion.

This symposium does take a broad look at a wide spectrum of the issues concerned with abortion. Recent developments including the concept of 'wrongful life' are introduced and discussed. The long-term effects of abortion on both the woman and her partner are also discussed in an interesting contribution by Janet Mattinson. And the role of the doctor is discussed briefly: 'many people prefer the doctors to make the choice for them. It is not just a question of altering attitudes, but of helping people to grow up and make choices'. This comment, made by a Jungian analyst, left me with an uncomfortable feeling that she believed that doctors had some particular expertise in this area.

Overall, this book must be welcomed for it does try to look at issues that are less than comfortable and to convey the dilemmas and quandaries that the personnel involved in abortion often face. Statistics are also included which should form a helpful reference source. There is also a surprisingly good index which is unusual in a book of this type. One is left, though, feeling that the contributors never allowed themselves to personalise the subject; it was discussed from a distance as if abortions happened to other people and were performed by other doctors. It is a sad omission that there was no attempt to find out what the effect is on doctors of performing abortions as a part of their routine work.

KATE NEWSON

Director of Midwifery Services, The London Hospital (Mile End), Bancroft Road, London E1 4DG.

\section{Betrayers of the Truth: Fraud and Deceit in Science}

William Broad and Nicholas Wade, 256 pages, Oxford, £3.95, Oxford University Press, 1985.

This book is at once a piece of investigative journalism and an attempt to produce a critique of certain widely held beliefs about the nature of science. As the former it makes fascinating reading - who doesn't enjoy seeing the misdeeds of others, especially the great and famous, uncovered? As the latter it provides food for serious thought in two areas. First in the realm of philosophy of science, second in the realm of medical ethics.

The authors present a series of cases of malpractice in the conduct of scientific research, from the doctoring of results on the one hand to the total invention of whole experiments and projects on the other; from claiming credit for the research of others, on the part of supervisors or heads of research teams to the plagiarism of papers by editors and referees and by deft use of obscure journals as sources and repositories of publications.

But what bearing do such revelations have upon the philosophical account one gives of the status of scientific theories and of scientific knowledge? The widely held view that science offers us value-free information about the world; that it employs only rigorous procedures in the production of theories; that its hypotheses are constantly subject to refutation by experimental testing could withstand reports of a few aberrant practitioners. But when Galileo, Newton, Dalton, Mendel and J B Watson are cited as examples of scientists who selected, improved and even forged data in accordance with theoretical convictions, the many recent cases presented take on a more considerable significance. Such a gap between philosophical theory and scientific practice is rightly seen as implausible. Given that the philosopher's work is essentially descriptive then no doubt such information as is reported in this volume must favour the account of scientific activity offered by Kuhn rather than that offered by Popper.

The explanations of these activities proffered by the authors apply equally to the world of medicine. The academic rat-race of publishing in order to establish careers and reputations has led to the appearance of no less than eight thousand journals in medicine. Authors have become adept at dividing one modest publication into three or four papers containing minimal publishable material. Co-authorships now average five authors in some medical journals. Such proliferation makes it impossible to check the authenticity of both authorship and results. Serious cases of fraudulent research from such halls of fame as the Yale and Harvard Medical Schools are attributed to this source of corruption.

The structure of research teams puts pressure on ambitious young researchers to produce results favourable to projects in hand. Lack of kudos in the mere replication of the results of others and the priority placed on originality means that little testing of the work of others occurs except with a view to improving on their results and developing their theories. These pressures are as real in medical research as elsewhere in science. The book reviews celebrated cases of fraud in the research into cancer, transplantation, drug safety and psychology resulting in the waste of large amounts of research money and the releasing of dummy hares for serious researchers to waste their time and energy chasing. In addition they may offer serious threats to public health.

But what are the cures? Here the authors' suggestions are rather thin. And who can blame them? Short of radical changes in the structure of 
publishing practice and of research funding unscrupulous careerists will continue to prosper.

DONALD EVANS

Department of Philosophy, University College, Cardiff.

\section{Doctors' Dilemmas: Medical Ethics and Contemporary Science}

\author{
Melanie Phillips and John Dawson, \\ Brighton, ix and 230 pages, \\ $£ 8.95$ paperback, $£ 22.00$ hardback, \\ Harvester Press, 1985
}

This book, written by a journalist and a doctor in collaboration, has two main aims. One is to survey five main problem areas in medical ethics - life and death issues (whether killing and letting die are morally equivalent and whether there is always an obligation to save life); the ethics of research and experimentation; the relations between doctors and the State, especially in prisons; the obligation to tell patients the truth; and the problem of the allocation of limited resources. The book provides a useful survey of the moral problems in these areas; and we should be particularly grateful for the coverage of the last three, which have not received as much attention as other parts of medical ethics. There are also many sensible comments en route, such as the discussion of the role of moral philosophy on pp 17-19.

The second aim is to argue for a mechanism whereby the consensus of society on these issues can be obtained and applied, in order that an appropriate decision may be reached: it is accepted that this process would involve compromising between various points of view and also will be on-going, since societies do not settle moral questions once and for all. This makes an important point: there is a need for patients, and for society at large, to become more involved in medical decision-making, particularly, perhaps, with regard to general principles. Unfortunately, the point is made in an exaggerated way, and the arguments used are, one has to say, slovenly. The slovenliness appears in three areas.

First, the authors' understanding of the people they criticise is poor. On p 5 a passage from the BMA handbook, Medical Ethics, 1970, is called 'paternalistic, insular complacency'; but it is not about relations between doctors and patients at all, but about relations between doctors themselves.
John Harris does not 'argue inexorably for infanticide' ( $p$ 38), but argues that infanticide and withholding nourishment are morally equivalent: he inclines to the view that both are wrong. The judge in the Arthur case (p 44), in directing the jury that it was lawful to withhold nourishment if, among other conditions, the child was rejected by its parents, was not implying that the child had no rights, but merely that what was in its best interests depended in part on the willingness of the parents to care for it. And - a final example - the authors' further comments on the judge's directions seem to ignore the difference between necessary and sufficient conditions.

Secondly, there is a cavalier attitude to rational argument. Positions are taken up not because of their merits but because they yield the conclusions the authors want. Thus in chapter 2 they uphold the moral distinction between killing and letting die, but in chapter 5 reject the much more plausible distinction between lying and withholding information: this may be consistent, but reasons need to be given. Most seriously, they opt for abandoning logic altogether when it leads to conclusions they dislike, such as the conclusion that killing and letting die are morally equivalent. This is both disreputable and unnecessary, as is shown by the points quoted from Lorber on p 38: if correct, Lorber's arguments would show precisely that the consequences of infanticide would be worse than those of withholding nourishment, and therefore that the two are not equivalent. (What they do not show is that withholding nourishment is right).

Thirdly, there is a stigmatisation of ways other than consensus of deciding moral issues. Leaving issues to individual doctors is not 'moral anarchy': it is decision by individual conscience. A judge does not act in a 'moral vacuum' merely because he does not use, or does not know, the current moral consensus: he acts morally, using tradition, conscience or the law itself as his guide. Consensus is not the only way of making moral decisions, nor always the appropriate one. Thus, some areas of medical ethics involve the rights of individual patients and doctors, which should be upheld whether society likes it or not. Others involve detailed knowledge of individual circumstances, and are therefore best left to the discretion of the patients and/or doctors involved. Others involve so much technical knowledge that the medical profession itself is the best judge.
Certainly on some issues the view of society as a whole - if it has one and if it can be determined - would be extremely valuable; but only on some, not all. Moreover, there is no guarantee that the kind of body proposed on $p$ 190 , including 'doctors, scientists, other health professionals, theologians and others' (one hopes the 'others' include representatives of the old, the poor and the ill!), would in fact reach conclusions in line with those of society as a whole, useful though the deliberations of such a committee would be. In short, the authors do not make out their case, but we should be grateful to them for discussing the problems and putting forward their view, which deserves serious consideration.

A H LESSER Department of Philosophy, University of Manchester

\section{Soviet Psychiatric Abuse: the Shadow Over World Psychiatry}

Sidney Bloch and Peter Reddaway, 288 pages, London, £10.95, Victor Gollancz, 1984.

Bloch and Reddaway are probably the two most persistent and thorough campaigners against the abuse of psychiatry in the Soviet Union. They first brought Soviet practices to our attention in Russia's Political Hospitals (1977), an excellent account containing a large number of well documented case histories. Their new book is in the same fine tradition as the original. It provides an excellent contemporary historical assessment of the response to psychiatric abuse in the Soviet Union. What impresses is the objectiveness and detail of reporting. The authors examine the importance of the Sixth World Psychiatric Association (WPA) Congress in Honolulu in 1977, where there was a narrow vote to condemn Soviet psychiatric abuse. The WPA established a 'Committee to Review the Abuse of Psychiatry for Political Reasons'.

Bloch and Reddaway comprehensively document all of the major activities againt Soviet psychiatry that took place in the West between the Honolulu and subsequent Vienna World Psychiatric Congress. Much of 